\title{
Predictors of Pegylated Interferon Alpha and Ribavirin Efficacy and Long- Term Assessment of Relapse in Patients With Chronic Hepatitis C: A One- Center Experience From China
}

\author{
Qin Wu ${ }^{1}$; Feng Yu Zhan ${ }^{2}$; En Qiang Chen ${ }^{1}$; Cong Wang ${ }^{2}$; Zhen Zhen Li $^{2}$; Xue Zhong Lei ${ }^{1,}$ \\ ${ }_{1}^{1}$ Infectious Diseases Center, West China Hospital, Sichuan University, Chengdu, China \\ ${ }^{2}$ West China School of Medicine, West China Hospital, Sichuan University, Chengdu, China \\ ${ }^{*}$ Corresponding Author: Xue Zhong Lei, Infectious Diseases Center, West China Hospital, Sichuan University, P. O. Box: 610041, Chengdu, China. Tel: +86-2885423346, Fax: \\ +86-2885423052, E-mail: xzlei1117@sina.com
}

Received: March 23, 2015; Revised: April 18, 2015; Accepted: May 10, 2015

\begin{abstract}
Background: Sustained virological response(SVR) and virological relapse maintain pivotal roles in the management of chronic hepatitis $\mathrm{C}(\mathrm{CHC})$; however, there is little data regarding the long-term outcomes of patients with $\mathrm{CHC}$ in China.

Objectives:We aimed to investigate the predictive factors of therapeutic effect and viral relapse in patients who achieved end-of-treatment response (ETR).

Patients and Methods: We retrospectively analyzed clinical, biochemical and virological data of 169 adult patients with CHC from China who were not treated with pegylated interferon-alpha (PEG IFN- $\alpha$ ) and ribavirin, of which 142 achieved ETR and with a follow-up period ranging from six months to six years. Statistical analysis was performed by SPSS 20.0.

Results: Of the169 patients, 124 (73.4\%)achieved SVRand 23(16.2\%) experienced relapses post-therapy in cases of ETR patients. We considered sex, age, alanine aminotransferase, aspartate transaminase, baseline hepatitis C virus RNA level, HCV genotypes, IL28B rs12979860 genotype, rapid virological response (RVR), and early virological response (EVR). For antiviral effect in patients with CHC, $\mathrm{HCV}$ genotypes $(2,3)\left(\chi^{2}=\right.$ $11.285, \mathrm{P}=0.001)$, IL28B genotype (rs12979860 CC $)\left(\chi^{2}=16.552, \mathrm{P}<0.001\right), \operatorname{RVR}\left(\chi^{2}=37.339, \mathrm{P}<0.001\right)$, and $\operatorname{EVR}\left(\chi^{2}=70.265, \mathrm{P}<0.001\right)$ were significantly correlated with achieving SVR. For ETR patients with long-term follow-up, the relapse rate within six months was significantly higher than within other periods during six-year follow-up $\left(\chi^{2}=7.792, \mathrm{P}=0.005\right)$. Relapse was virtually not observed after therapy ceased for 48 weeks. The IL28B genotype (rs12979860 CT/TT) $(\mathrm{OR}=0.102$; 95\% CI, 0.031-0.339; P < 0.001), lower RVR $(\mathrm{OR}=0.239 ; 95 \% \mathrm{CI}, 0.078-0.738 ; \mathrm{P}$ $=0.013)$, and $\operatorname{EVR}(\mathrm{OR}=0.102 ; 95 \% \mathrm{CI}, 0.016-0.661 ; \mathrm{P}=0.017)$ were independent risk factors for relapse.

Conclusions: Our study comprehensively explored the predictive factors of therapeutic effect of administered drugs and analyzed viral relapse during a six-months to six-year follow-up period from China. The SVR may not be the perfect endpoint of HCV therapy in Chinese people; we recommend 48 weeks after treatment withdrawal as the suitable time point.
\end{abstract}

Keywords: Hepatitis C, Chronic; Follow-Up Studies; Recurrence; Interferon

\section{Background}

Infection with hepatitis $\mathrm{C}$ virus (HCV) is a grave public health problem and medical issue in the world. For years, the combination of pegylated interferon-alpha (PEG IFN- $\alpha$ ) and ribavirin was the standard of care (SoC) for chronic hepatitis $\mathrm{C}(\mathrm{CHC})(1,2)$. It is used to eradicate the infection, improve liver histology, and reduce risk of cirrhosis and hepatocellular carcinoma (3). This treatment regimen underwent a major change after the approval of direct antiviral agents (DAAs). DAAs inhibit specific steps in the HCV life cycle. Although triple therapy with DAAs increases sustained virological response (SVR) rate with decreased duration of therapy $(4,5)$, it brings significant adverse effects and increases the rate of becoming resistance variation. Furthermore, DAAs are expensive and are not yet available in many countries (6). The dual therapy as the classical approach is still the first line of treatment in China.
The commonly used endpoint for assessing efficacy is SVR, defined by the extinction of HCV-RNA six months after stopping treatment. Patients achieving SVR are considered to be virologically cured (7). However, a considerable number of patients fail to achieve SVR for viral breakthrough and unresponsiveness during treatment. In the follow-up of treatment with PEG IFN- $\alpha$ and ribavirin, some patients experience virological relapse after achievement of end-of-treatment response (ETR) even after SVR. Relapse, however, remains one of the leading issues in the treatment of patients with CHC. In order to reach SVR and avoid relapse, it is recommended to prolong the period of therapy for some "hard-to-treat" cases $(8,9)$. Long-term administration of PEG IFN- $\alpha /$ ribavirin increases the cost of treatment and the risk of serious adverse effects. Therefore, it is of great utility to effectively predict, either before or during treatment and follow-up,

Copyright (C) 2015, Kowsar Corp. This is an open-access article distributed under the terms of the Creative Commons Attribution-NonCommercial 4.0 International License (http://creativecommons.org/licenses/by-nc/4.0/) which permits copy and redistribute the material just in noncommercial usages, provided the original work is properly cited. 
Wu Q et al.

whether a patient will achieve an SVR and virus will be detectable again in patients. Several studies have defined the pretreatment patient features, such as viral genotypes and subjects with favorable IL28B genotypes, markedly affect the likelihood of attaining a SVR $(1,10-12)$. On-therapy kinetics of antiviral response also plays an important role; the rapid and early virological response are the most important factors (13-15). Moreover, although the relapse rate over time is one of the most important problems, which is clinicians' concern, little is known about the effect of these values on relapse in the management of long-term follow-up.

\section{Objectives}

We have therefore conducted a retrospective and consecutive cohort study to assess the predictability of response to PEG IFN- $\alpha /$ ribavirin and relapse in patients with CHC. In addition, we retrospectively establish the prevalence of relapse among patients with ETR in the 24to 288-week follow-up to provide clinical data to improve clinical outcomes.

\section{Patients and Methods}

\subsection{Patients}

Between February 2008 and March 2013, 169 previously untreated adult patients with $\mathrm{CHC}$ were consecutively treated with the combination of PEG IFN- $\alpha$ (2a or $2 \mathrm{~b}$ ) and ribavirin. They were followed up continuously before or after the end of treatment (at least 24 weeks) and nobody terminated treatment due to incompliance; therefore, the available data were comparable and complete. All of the patients enrolled at the Hepatology Outpatient Clinic of West China Hospital, Sichuan University, Chengdu, Sichuan, which is one of the largest governmental hospital in China. The diagnosis of CHC was based on serologic, biochemical, and virologic information according to the European association for the study of the liver (EASL) clinical practice guidelines: Management of hepatitis C infection, 2011. Exclusive criteria were as follows: co-infection with other hepatitis viruses or HIV; alcohol abuse (30 g/d); active intravenous drug use; severe hepatitis or cirrhosis; hepatocellular carcinoma; severe neuropsychiatric disorders; pregnancy or breast-feeding; poorly controlled thyroid disease or autoimmune diseases; uncontrolled depression; and hypersensitivity to Peg-IFN or ribavirin.

This study was approved by the ethics committee of West China Hospital of Sichuan University and each participant gave informed consent at data analysis according to the Helsinki declaration.

\subsection{Laboratory Evaluation}

Patients were tested for blood parameters, i.e., haemoglobin (Hb) level, white blood cell (WBC) count, and platelet (Plt) count, blood chemistry tests, ie, serum levels of creatinine (Cr), albumin (Alb), aspartate aminotransferase (AST), alanine aminotransferase (ALT), $\gamma$-glutamyltransferase (GGT), total cholesterol (Chol), and triglycerides (TG), thyroid function and autoimmune inhibitors at fourth and twelfth week, and then at three-month interval. In addition, they were assessed at fourth, 12th and 24th week and then every year after therapy. Eligible subjects were those with positive results for anti-HCV antibody in serum by chemiluminescence (Anti-HCV, Cobas, Roche Diagnostics GmbH, Germany). Serum HCV RNA was tested by quantitative and qualitative reverse transcriptase polymerase chain reaction (Ampliprep, Taqman, Roche Molecular Systems, Branchburg, the United States) with a lower limit of sensitivity of 100 viral copies/mL (50 IU/mL). HCV genotyping was done using reverse hybridization (INNO-LiPA, Innogenetics, Ghent, Belgium). All of the procedures were operated in strict accordance with the instructions. The IL28B SNP rs12979860 genotyping was detected by real-time allelic discrimination assay (TaqMan SNP Genotyping Assay, Applied Biosystems, Foster City, California, US) on a CFX96 Real-time PCR instrument (BioRad Laboratories, Hercules, California, US). The primers (Con F: GCTTATCGCATACGGCTAGG-3, Con R: CACAATTCCCACCACGAGAC-3) were included in $50 \mu \mathrm{L}$ reaction volume designed by Invitrogen Biotech Company (Shanghai, China).

\subsection{Study Design}

This was a retrospective cohort study. All study patients underwent laboratory tests including determination of anti-HCV levels, HCV-RNA levels, HCV genotyping, IL28B SNP rs12979860 genotyping, determination of blood cell counts, serum ALT, determination of thyroid function including levels of thyroid stimulating hormone (TSH), free triiodothyronine (FT3), and free thyroxine (FT4), determination of autoimmune inhibitors including autoantibody to nuclear antigen (ANA), and extractable nuclear antigen (ENA).

Patients were treated with $180 \mu$ g of PEG IFN- $\alpha-2 a$, or $1.5 \mu \mathrm{g} / \mathrm{kg}$ of PEG-IFN- $\alpha$-2b subcutaneously once a week, while genotypes 1 and 6 received ribavirin at a dosage of 1000 to $1200 \mathrm{mg} / \mathrm{d}$ (based on body weight: $1000 \mathrm{mg} / \mathrm{d}$ for those $\leq 75 \mathrm{~kg}$ or $1200 \mathrm{mg} / \mathrm{d}$ for those $>75 \mathrm{~kg}$ ) for 48 weeks and genotypes 2 and 3 received ribavirin at a dosage of $800 \mathrm{mg} / \mathrm{d}$ for 24 weeks. Dose modification or discontinuation of PEG-IFN and ribavirin were done at the discretion of each physician. All laboratory assessments were repeated at fourth and twelfth weeks, and then every three months of treatment. In addition, they were assessed in the serum at fourth, 12th, and 24th week and then every year after discontinuing the treatment. Grouping on treatment efficacy and relapse based on HCV RNA level.

\subsection{Definitions}

Rapid virological response (RVR) was defined as HCV RNA negativity at week four of treatment; early virologi- 
Wu Q et al.

cal response (EVR) was defined as HCV RNA negativity at week 12 of treatment; ETR was defined as HCV RNA negativity at the end of treatment; SVR was defined as undetectable HCV RNA for 24 weeks after ETR. Non-responsive was defined as a patient who failed to achieve a decline of $2 \log _{10}$ HCV RNA IU/mL after 12 weeks of treatment or who never achieved undetectable HCV RNA during treatment duration of 24 weeks. Breakthrough (BT) was defined as reappearance of HCV RNA at any time during treatment after virological response. A relapse referred to detectable HCV RNA in serum after treatment discontinued and an ETR documented.

\subsection{Clinical Follow-Up}

Patients were asked to have follow-up of serologic, biochemical, and virologic test at fourth, 12th, and 24th week and then at least once a year after the treatment stopped. The period of follow-up ranged from six months to six years.

\subsection{Statistical Analysis}

Continuous variables across the treatment were provided as mean $\pm S D$, and categorical variables as percentages. An analysis of variance was applied to continuous variables of the baseline factors in comparison to control groups and Chi square or Fisher's exact tests were suitable for categorical variables. Efficacy of combination antiviral therapy (coded as 1, SVR; or 0, without SVR), relapse (coded as 1 , relapse; or 0 , without relapse) and non-response (coded as 1, non-response; or 0, response) were identified as dependent variable in binary logistic regression model. Several variables (age, sex, serum ALT, AST, and HCV RNA levels, HCV genotypes, IL28B rs12979860 genotype CC, and the presence or absence of RVR or EVR) were identified as independent variables. The results were presented as odds ratio (OR) and $95 \% \mathrm{CI}$. Cumulative incidence of relapse was plotted using the Kaplan-Meier method. All P values were two-tailed and statistically significance was accepted at P $\leq$ 0.05. Data analyses were performed using the SPSS 20.0 (SPSS Inc, Chicago, Illinois, US).

\section{Results}

\subsection{Clinical Characteristics and Response Rates}

A total of 169 patients who had never received treatment were analyzed in this study. Patients received combination therapy with PEG IFN- $\alpha$ (2a or $2 \mathrm{~b}$ ) and ribavirin. The follow-up duration lasted at least 24 weeks and at most six years. Table 1 presents the results obtained from the preliminary analysis of demographics, biochemical, and virological data. For IL28B rs12979860, the frequencies of polymorphisms were $82.8 \%$ for the CC type and $17.2 \%$ for the CT/TT type. The response rate across the treatment at the end of the follow-up was as follows: 99 patients out of 169 (58.6\%) had an RVR, 139 (82.2\%) had an EVR, 142 (84.0\%) achieved an ETR, 22 (13.0\%) were non-response, 5 (3.0\%) experienced viral breakthrough during treatment, 124 (73.4\%) achieved an SVR, and relapses were observed in 23 patients after cessation of treatment. The prevalence of relapse in cases of ETR was 16.2\% (Figure 1).

Table 1. Baseline Characteristics of Patients With Chronic Hepatitis C Infection ${ }^{\mathrm{a}}$

\begin{tabular}{|c|c|}
\hline Variable & Patients $(N=169)$ \\
\hline Sex, male, \% & 54.4 \\
\hline Age, $y^{b}$ & $43.22 \pm 12.97$ \\
\hline ALT, IU/L, b & $78.15 \pm 73.53$ \\
\hline AST, IU/L, b & $69.28 \pm 67.08$ \\
\hline HCV-RNA, log10IU/mL b & $6.19 \pm 1.02$ \\
\hline$\geq 6 \times 105 \mathrm{IU} / \mathrm{mL}, \%$ & 71.6 \\
\hline$<6 \times 105 \mathrm{IU} / \mathrm{mL}, \%$ & 28.4 \\
\hline \multicolumn{2}{|l|}{ HCV genotypes [case (\%)] } \\
\hline 1,6 & $133(78.7)$ \\
\hline 2,3 & $36(21.3)$ \\
\hline \multicolumn{2}{|l|}{ IL28B genotypes [case (\%)] } \\
\hline $\mathrm{CC}$ & $140(82.8)$ \\
\hline $\mathrm{N}-\mathrm{CC}$ & $29(17.2)$ \\
\hline \multicolumn{2}{|c|}{$\begin{array}{l}\text { a Abbreviations: ALT, alanine aminotransferase; AST, aspartate } \\
\text { transaminase; and IL28 CC, CC genotype of interleukin } 28 \text { single } \\
\text { nucleotide polymorphism. } \\
\text { b Values are presented as mean } \pm \text { SD or No. (\%). }\end{array}$} \\
\hline
\end{tabular}

Figure 1. Percentages of Patients in On-Treatment Population $(\mathrm{n}=169)$ Presenting Rapid Virological Response, Early Virological Response, End-of-Treatment virological Response, Non-Response, Breakthrough, Sustained Virological Response, and Relapse

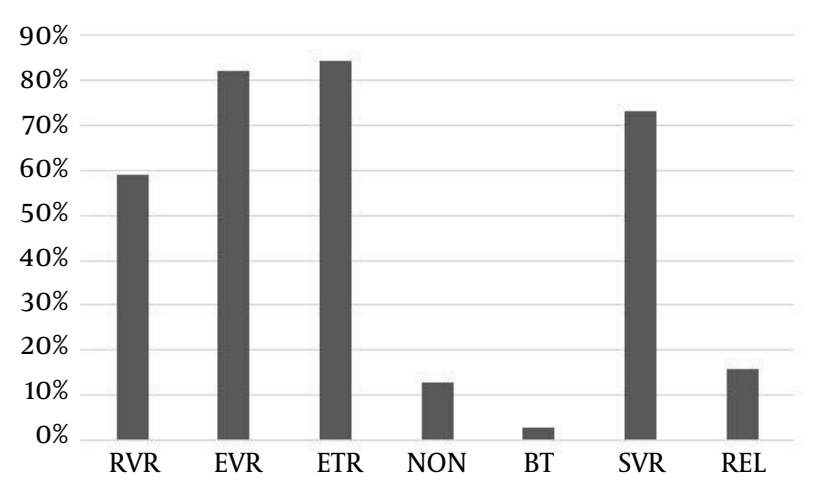

BT, breakthrough; ETR, end-of-treatment virological response; EVR, early virological response; NON, non-response; REL, relapse; RVR, rapid virological response; SVR, sustained virological response. 
Wu Q et al.

\subsection{Predictive Factors Associated With Antiviral Combination Treatment}

To explore the predictive factors based on antiviral combination treatment, we evaluated SVR according to demographic data and virology data as well as viral kinetics on-therapy. Demographic and virology data included age, sex, serum ALT, AST, and HCV RNA levels, IL28B genotypes, and HCV genotypes, and viral kinetics included the presence or absence of RVR or EVR (Table 2).

We considered patients with SVR separately from those without SVR. Pretreatment factors and on-treatment virological response that might identify potential predictors of antiviral efficacy were compared between two groups. According to the results showed in Table 2, there were no significant differences in age, sex, and serum ALT, AST, and HCV RNA levels between groups. On univariate analysis, HCV genotypes $(P=0.001)$, IL28B genotypes $(P<0.001)$, $\operatorname{RVR}(\mathrm{P}<0.001)$, and EVR $(\mathrm{P}<0.001)$ were associated with SVR. On multivariate analysis, AST level $(\mathrm{OR}=0.993 ; 95 \% \mathrm{CI}$, 0.987- 0.999; $\mathrm{P}=0.032$ ), IL28B genotype (CC: $\mathrm{OR}=6.977 ; 95 \%$ $\mathrm{CI}, 2.111$-23.057; $\mathrm{P}=0.001)$, HCV genotype $(\mathrm{OR}=7.057 ; 95 \% \mathrm{CI}$, 1.165 - 42.748; $\mathrm{P}=0.033), \mathrm{RVR}(\mathrm{OR}=3.018 ; 95 \% \mathrm{CI}, 1.075$ - 8.476; $\mathrm{P}=0.036)$, and $\mathrm{EVR}(\mathrm{OR}=39.750 ; 95 \% \mathrm{CI}, 8.561-184.565 ; \mathrm{P}$ $<0.001$ ) were independent predicting factors (Table 3 ). The positive predictive value of RVR was $89.9 \%$, and that of EVR was 87.1\%; there was no significant difference between them $(\mathrm{P}>0.05)$. The negative predictive value of RVR was $50.0 \%$, which was significantly lower than that of EVR (90.0\%) according to Table $4\left(\chi^{2}=14.261, \mathrm{P}<0.001\right)$.

\begin{tabular}{|c|c|c|c|c|c|c|c|c|c|}
\hline \multirow[t]{2}{*}{ Factor } & \multicolumn{3}{|c|}{ SVR } & \multicolumn{3}{|c|}{ Non-Response } & \multicolumn{3}{|c|}{ Relapse } \\
\hline & $\begin{array}{r}\text { Patients } \\
\text { With SVR } \\
(\mathrm{N}=124)\end{array}$ & $\begin{array}{c}\text { Patients } \\
\text { Without SVR } \\
\quad(N=45)\end{array}$ & $\mathbf{P}$ & $\begin{array}{c}\text { Non-Response } \\
\text { Patients } \\
(\mathbf{N}=\mathbf{2 2})\end{array}$ & $\begin{array}{c}\text { Response } \\
\text { Patients } \\
(\mathrm{N}=147)\end{array}$ & $\mathbf{P}$ & $\begin{array}{l}\text { Patients With } \\
\text { Relapse } \\
(\mathbf{N}=\mathbf{2 3})\end{array}$ & $\begin{array}{l}\text { Patients Without } \\
\text { Relapse } \\
(\mathbf{N}=119)\end{array}$ & $\mathbf{P}$ \\
\hline Age, y & $43 \pm 13$ & $44 \pm 13$ & 0.573 & $49 \pm 11$ & $42 \pm 13$ & $0.029^{b}$ & $43 \pm 15$ & $42 \pm 13$ & 0.736 \\
\hline Sex (male: female) & $68: 56$ & $24: 21$ & 0.862 & $10: 12$ & $82: 65$ & 0.364 & $14: 9$ & $65: 54$ & 0.581 \\
\hline ALT, IU/L & $76 \pm 74$ & $84 \pm 72$ & 0.460 & $71 \pm 68$ & $79 \pm 74$ & 0.615 & $80 \pm 77$ & $77 \pm 75$ & 0.333 \\
\hline AST, IU/L & $66 \pm 67$ & $78 \pm 67$ & 0.226 & $67 \pm 58$ & $70 \pm 68$ & 0.870 & $75 \pm 77$ & $67 \pm 67$ & 0.435 \\
\hline $\begin{array}{l}\text { HCV-RNA, log10, } \\
\text { IU/mL }\end{array}$ & $7.4 \pm 1.6$ & $8.8 \pm 1.6$ & 0.610 & $6.5 \pm 0.7$ & $6.1 \pm 1.0$ & 0.077 & $7.9 \pm 1.5$ & $7.5 \pm 1.6$ & 0.880 \\
\hline $\begin{array}{l}\text { HCV genotypes } \\
(1,6 / 2,3)\end{array}$ & $90 / 34$ & $43 / 2$ & $0.001^{b}$ & $22 / 0$ & $111 / 36$ & $0.009^{b}$ & $20 / 3$ & $88 / 31$ & 0.181 \\
\hline $\begin{array}{l}\text { IL28B genotypes(CC/ } \\
\mathrm{N}-\mathrm{CC})\end{array}$ & $112 / 12$ & $28 / 17$ & $<0.001^{b}$ & $13 / 9$ & $127 / 20$ & $0.002^{b}$ & $14 / 9$ & $109 / 10$ & $<0.001^{b}$ \\
\hline RVR (RVR/N-RVR) & $89 / 35$ & $10 / 35$ & $<0.001^{b}$ & - & - & - & $8 / 15$ & $87 / 32$ & $<0.001^{b}$ \\
\hline EVR (EVR/N-EVR) & $121 / 3$ & $18 / 27$ & $<0.001^{b}$ & - & - & - & $18 / 5$ & $117 / 2$ & $<0.001^{\mathrm{b}}$ \\
\hline
\end{tabular}

a Abbreviations: ALT, alanine aminotransferase; AST, aspartate transaminase; CC genotype of interleukin 28 single nucleotide polymorphism; EVR, early virologic response; IL28 CC; SVR, sustained viral response; RVR, rapid virologic response.

b Statistically significance was presented.

\begin{tabular}{|c|c|c|c|c|c|c|}
\hline \multirow[t]{2}{*}{ Factor } & \multicolumn{2}{|l|}{ SVR } & \multicolumn{2}{|c|}{ Non-Response } & \multicolumn{2}{|l|}{ Relapse } \\
\hline & OR $(95 \% \mathrm{CI})$ & $\mathbf{P}$ & OR $(95 \% \mathrm{CI})$ & $\mathbf{P}$ & OR $(95 \% \mathrm{CI})$ & $\mathbf{P}$ \\
\hline Age & NA & NA & $1.050(1.008-1.094)$ & $0.020^{b}$ & NA & NA \\
\hline AST & $0.993(0.987-0.999)$ & $0.032^{b}$ & NA & NA & NA & NA \\
\hline IL28B genotypes (CC/N-CC) & $6.977(2.111-23.057)$ & $0.001^{b}$ & $0.199(0.069-0.577)$ & $0.003^{b}$ & $0.102(0.031-0.339)$ & $<0.001^{b}$ \\
\hline HCV genotypes $(1,6 / 2,3)$ & $7.057(1.165-42.748)$ & $0.033^{b}$ & NA & NA & NA & NA \\
\hline RVR (RVR/N-RVR) & $3.018(1.075-8.476)$ & $0.036^{b}$ & NA & NA & $0.239(0.078-0.738)$ & $0.013^{b}$ \\
\hline EVR(EVR/N-EVR) & $39.750(8.561-184.565)$ & $<0.001^{\mathrm{b}}$ & NA & NA & $0.102(0.016-0.661)$ & $0.017^{\mathrm{b}}$ \\
\hline
\end{tabular}

a Abbreviation: AST, aspartate transaminase; EVR, early virologic response; IL28 CC, CC genotype of interleukin 28 single; OR, odds ratio; RVR, rapid virologic response; and NA, not applicable.

b Statistically significance was presented. 
Wu Q et al.

\begin{tabular}{|c|c|c|c|c|c|c|c|c|}
\hline \multirow[t]{2}{*}{ Predictive Value } & \multicolumn{4}{|c|}{ SVR } & \multicolumn{4}{|c|}{ Relapse } \\
\hline & RVR & EVR & $\chi^{2}$ & $\mathbf{P}$ & RVR & EVR & $\chi^{2}$ & $\mathbf{P}$ \\
\hline Positive, \% (ratio) & $89.9(89 / 99)$ & $87.1(121 / 139)$ & 0.452 & 0.501 & $8.4(8 / 95)$ & $13.3(18 / 135)$ & 1.342 & 0.247 \\
\hline Negative, \% (ratio) & $50.0(35 / 70)$ & $90.0(27 / 30)$ & 14.261 & $0.001^{b}$ & $68.1(32 / 47)$ & $28.6(2 / 7)$ & 4.079 & $0.043^{b}$ \\
\hline
\end{tabular}

a Abbreviations: SVR, sustained virological response; EVR, early virologic response; and RVR, rapid virologic response.

b Statistically significance was presented.

A considerable number of patients failed to achieve SVR for never achieving undetectable HCV RNA levels in combination therapy. We separated responder from nonresponder patients; the comparison results are shown in Tables 2 and 3. There are no significant differences in sex and serum ALT, AST, and HCV RNA levels between two groups. On univariate analysis, age $(\mathrm{P}=0.029)$, HCV genotypes $(\mathrm{P}=0.009)$, and IL28B genotypes $(\mathrm{P}=0.002)$ were associated with non-responsiveness (Table 2). On multivariate analysis, old age $(\mathrm{OR}=1.050 ; 95 \% \mathrm{CI}, 1.008-1.094$; $\mathrm{P}=0.020)$ and IL28B genotype (N-CC: OR $=0.199 ; 95 \% \mathrm{CI}$, $0.069-0.577 ; \mathrm{P}=0.003$ ) were independent risk predicting factors for non-responsiveness (Table 3 ).

\subsection{Predictive Factors Associated With Relapse}

The median duration of follow-up was 22.93 months (range, 6 - 72 months). The overall rate of relapse was 13.6\% (23/169) in the study cohort, while a recurrence of HCV RNA rate in cases of ETR was $16.20 \%$ (23/142). The earliest time of detectable HCV RNA was at the first month followup, the latest was at 48th month. Twenty-three patients had recurrence during follow-up 56.5\% of which (13/23) relapsed between zero and 12 weeks after treatment, $21.7 \%$ (5/23) between weeks 12 and 24, and 17.4\% (4/23) between 24 and 48 weeks. Otherwise, HCV RNA remained at undetectable levels at follow-up from two to six years, except in one patient $(1 / 23)$ in whom it was detected at fourth year. The relapse rate within six months was significantly higher than other periods during six years of follow-up $\left(\chi^{2}=7.792, \mathrm{P}=0.005\right)$. The cumulative rate of relapse increased more rapidly within six months and gradually slowed down in the subsequent period. The rate peaked at the 12th month follow-up and tended towards stability (Figure 2).

We categorized patients with relapse separately from those without relapse, the comparison results between the two groups are given in Tables 2 and 3. Baseline characteristics of patients were unrelated to a higher risk of relapse, except IL28B genotype ( $\mathrm{P}<0.001)$; meanwhile, the viral kinetics including RVR and EVR were related factors of relapse (both $\mathrm{P}<0.001)$. Furthermore, we constructed a stepwise logistic regression analysis model to assess the impact factors of relapse rates. The model selected IL28B genotype $(\mathrm{OR}=0.102 ; 95 \% \mathrm{CI}, 0.031-0.339 ; \mathrm{P}$
$<0.001)$, RVR

Figure 2. The Cumulative Relapse Rate of Patients With End-of-Treatment Virological Response at a Follow-Up Ranged From Six to Seventy-Two Months

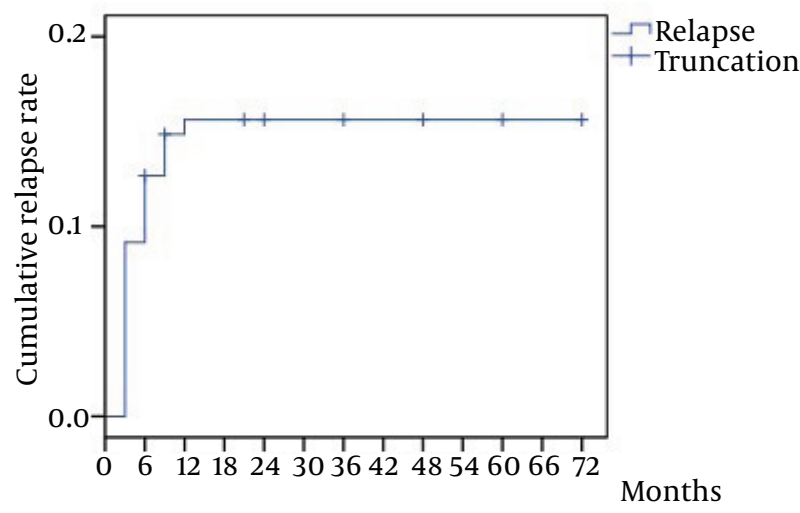

Cumulative incidence of relapse was plotted using the Kaplan-Meier method.

$(\mathrm{OR}=0.239 ; 95 \% \mathrm{CI}, 0.078-0.738 ; \mathrm{P}=0.013)$, and $\mathrm{EVR}(\mathrm{OR}=$ 0.102 ; $95 \% \mathrm{CI}, 0.016-0.661 ; \mathrm{P}=0.017)$ as the negative predictor of relapse (Table 3 ). The positive predictive value of RVR and EVR were respectively $8.4 \%$ and $13.3 \%$ with no significant difference between them $(\mathrm{P}>0.05)$. The negative predictive value of RVR was 68.1\%, which was significantly higher than that of EVR (28.6\%) $\left(\chi^{2}=4.079, \mathrm{P}=0.043\right.$; Table 4).

\section{Discussion}

SVR and relapse maintain pivotal roles in the management of CHC infection. Thus, the prediction of achieving SVR and relapse are important to reduce adverse effects and therapy expenses. In China, PEG-IFN/ribavirin treatment, as the classical regimen, is still the first line of therapy; however, there was little data regarding the outcomes of long-term follow-up in CHC patients. In this study, we comprehensively explored the predictive factors of therapeutic effect and analyzed viral relapse during a six-month to six-year follow-up.

Non-responsiveness is an important component part 
Wu Q et al.

of failing to achieve sustained viral response. Sezaki et al. (16) had explored response to treatment in patients with PEG-IFN/ribavirin in terms of age and sex. Their results showed male patients were more inclined to achieve SVR; regarding age, older patients had a lower tendency to achieve antivirus response. In the present study, the nonresponsiveness was not associated with sex, but it was significantly associated with age. Therefore, age influences the severity of CHC. Older patients have faster disease progresses and poorer response to antiviral therapy. This phenomenon demonstrates the benefits of early intervention of treatment.

The SVR rates have been reported to vary depending on genotype. According to EASL guidelines, SVR rates are considerably higher in patients infected with HCV genotypes 2,3 , and 5 than in patients with genotype 1 (10). American Association for the Study of Liver Diseases (AASLD) guidelines indicate that SVR is achieved in $40 \%$ to $50 \%$ of patients infected with genotype 1 and in $80 \%$ or more patients infected with genotypes 2 and 3 (17). The SVR rates were $44 \%$ to $79 \%$ in Asian patients with genotype 1 and $75 \%$ to $94 \%$ in Asian patients with genotype 2 and 3 (18). These data suggest that genotype is a strong predictive factor of SVR.

In the present study, the overall SVR rate was $73.4 \%$ in all genotypes, $67.7 \%$ in genotype 1 and 6 , and $94.4 \%$ in genotype 2 and 3. Patients with genotype 1 and 6 had significantly lower SVR rates compared to patients with genotype 2 and $3(P=0.001)$. Breaking the data down even further, we found no genotype 2 or 3 existing in non-responsive patients. It can further illustrate the role of HCV genotypes in combination treatment.

The heterogeneity in response to SoC treatment among different ethnic or racial groups can be partially explained by the finding that SVR rates are influenced by host genetic polymorphisms located upstream of the IL28B gene, which vary between different populations worldwide. We demonstrated that response rates and SVR rates were significantly higher in patients with IL28B rs12979860 genotype CC compared to patients with CT/TT ( $86.4 \%$ vs. $40.9 \%$ and $90.3 \%$ vs. $37.8 \%$, respectively). This result was similar to that of De Nicola et al.(19) whose study showed that patients with CC genotype achieved significantly higher SVR rates compared to patients with CT/TT (88\% vs. 38\%, $\mathrm{P}<0.001$ ). Although the exact mechanisms behind this association are still only partially understood, there is unanimous agreement that IL28B genotypes were related to IFN-stimulated gene expression.

Therapeutic response can efficiently predict the outcome of therapy (20). Fried et al. (21) performed a retrospective analysis on 1383 patients and concluded that RVR was frequently an indication of EVR and could predict SVR (OR = 5.47; 95\% CI, 3.97 - 7.52). Patients who become HCV-RNA negative after four and 12 weeks have a better chance of achieving an SVR. Our study confirmed that the patients who achieved RVR and EVR are more likely to have SVR than those who did not. This result was consis- tent with the previous reports $(20,21)$. Although we found that the positive predictive values of RVR were higher than those of EVR for all patients, which suggested that the earlier the patients gained virological response the more likely they gained SVR, there was no significant difference between them. This phenomenon demonstrates that the positive predictive values on SVR for RVR are similar to that of EVR. The negative predictive of RVR was relatively lower, while EVR had a stronger negative predictive value. It seems reasonable for those patients who did not achieve EVR to extend treatment for another 24 weeks (after treating for 12 weeks, HCV RNA is positive in serum, but drops $\geq 2 \log _{10}$ in comparison to the pretreatment baseline) or stop treatment (up to week 12 of treatment patient do not achieve a $2 \log _{10}$ drop in HCV RNA) to cease costs and adverse reactions, because there is slight chance of achieving SVR under this condition according to our study. It is also in agreement with EASL clinical practice guidelines. Moreover, stepwise logistic regression analysis about impact factors of SVR rate showed AST level as an emerging element $(\mathrm{P}=0.032)$, which was not common in other studies. The AST level effect on SVR can be verified by further study with larger sample size.

It is encouraging to eradicate HCV-RNA during the antiviral therapy, but at the follow-up of treatment with PEG IFN- $\alpha$ and ribavirin, a considerable number of patients experience HCV recurrence after achievement of ETR even after SVR. Relapse, however, still remains a big problem for destroying confidence of patients with relapses and increasing the family and social economic burden. It is of great importance to analyze and predict relapses in the long-term follow-up. In our study, the prevalence of relapse in cases of ETR was $16.2 \%$, which was consistent with previous report (22).

The duration of subsequent follow-up in these 169 patients ranged from six months to six years. The result of the present study shows that the highest percentage of relapses in patients who have received treatment with combination therapy occurs between week zero and week 24 of follow-up (78.3\%) ( $\mathrm{P}=0.005)$. It indicates reinforced follow-ups are imperative within six months of stopping treatment. Nonetheless, about $17.4 \%$ relapses had undergone virological rebound after six-month follow-up, which suggests that patients yet to have a risk of relapse even after SVR and follow-ups are still required. In our study relapse was not observed after therapy was ceased for 48 weeks, except one patient (1/142) who experienced relapse at fourth year. The most likely explanation is reinfection rather than relapse. Therefore, we can conclude that HCV infection relapses are virtually non-existent in patients in whom HCV RNA is not detected after stopping therapy for 48 weeks.

The SNP rs12979860, upstream of IL28B gene, was associated with relapse in $\mathrm{CHC}$ treatment. The distribution between favorable allele (rs12979860 C allele) and unfavorable allele (rs12979860 T allele) is different in recurrence populations. The IL28B genotype was found to be 
Wu Q et al.

highly predictive of relapse in this study. Moreover, our study indicated that individuals who achieved RVR/EVR had less chance to experience viral rebound. It suggested that the later the patients gained virological response, the more likely they experience relapse. Further analysis was performed to compare their predictive value. While the positive predictive values on relapse were similar in RVR and EVR, the negative predictive value of RVR was significantly higher than that of EVR. Although RVR had a stronger negative predictive value, the specificity is not high (68.1\%). Some reported age as a significant risk factor for relapse. Older age was an independent risk factor for relapse; the older patients responded poorly to antiviral therapy compared with young ones (23). However, the significance of age has been reported with inconsistent results (24). In our study, age has not been observed as a hazard. This discrepancy could be due to weak power of significance and/or differences in sample size. Although the relapse rate of HCV genotypes 1 and 6 were higher than that of genotypes 2 and 3, there was no significant difference between them.

Limitations of our study were its retrospective nature, limited sample size, and lack of histologic examinations in all patients. Despite those limitations, SVR was significantly higher in patients with HCV genotypes 2 or 3, IL28B genotype CC, RVR, or EVR. Relapse during the first six months was significantly higher than other periods during six years of follow-up, but still about $17.4 \%$ patients with relapses experienced virological rebound between 24 and 48 weeks of treatment cessation. Patients might have a risk of relapse even after SVR and follow-ups are required. However, the relapse rate was significantly lower in patients with IL28B genotype CC, RVR, or EVR.

Our study clearly demonstrates the followings:

1) The SVR rate is related to HCV genotypes, IL28B genotypes, RVR, and EVR. Testing virus and host genotypes and utilizing the high sensitivity of RVR and the high specificity of EVR may be valuable to individualize the duration of therapy.

2) Virological rebound is mainly experienced during the first six months of treatment discontinuation, but quite a number of proportion relapse happened between 24 and 48 weeks of therapy cessation. We can conclude that relapse is virtually non-existent in patients after therapy cessation for 48 weeks, and therefore, follow-ups within the 48 weeks are actually imperative not in China. Relapse is predictable by IL28B genotypes, RVR, and EVR.

\section{Acknowledgements}

We would like to thank the Hepatology Outpatient Clinic and Infectious Disease Center of West China Hospital, Sichuan University, for the supply of the database.

\section{Authors' Contributions}

Study concept and design: Qin Wu and Xue Zhong Lei. Analysis and interpretation of data: Qin Wu, Feng Yu
Zhan, and Cong Wang. Drafting the manuscript: Qin Wu and En Qiang Chen. Critical revision of the manuscript for important intellectual content: Xue Zhong Lei, Zhen Zhen Li, Feng Yu Zhan, and Cong Wang. Statistical analysis: Qin Wu, Feng Yu Zhan, and Cong Wang.

\section{References}

1. Ghany MG, Strader DB, Thomas DL, Seeff LB, American Association for the Study of Liver D. Diagnosis, management, and treatment of hepatitis C: an update. Hepatology. 2009;49(4):1335-74.

2. Sarrazin C, Berg T, Ross RS, Schirmacher P, Wedemeyer H, Neumann U, et al. [Prophylaxis, diagnosis and therapy of hepatitis $\mathrm{C}$ virus (HCV) infection: the German guidelines on the management of HCV infection]. Z Gastroenterol. 2010;48(2):289-351.

3. Lee YA, Friedman SL. Reversal, maintenance or progression: what happens to the liver after a virologic cure of hepatitis C? Antiviral Res. 2014;107:23-30.

4. Sulkowski MS, Gardiner DF, Rodriguez-Torres M, Reddy KR, Hassanein T, Jacobson I, et al. Daclatasvir plus sofosbuvir for previously treated or untreated chronic HCV infection. $N$ Engl J Med. 2014;370(3):211-21.

5. Gordon SC, Reddy KR, Jacobson IM, Poordad F, Bronowicki JP, Bacon B, et al. Boceprevir plus peginterferon alpha-2b/ribavirin in chronic hepatitis $C$ genotype 1 : impact of baseline viral load on sustained virologic response. J Clin Gastroenterol. 2014;48(5):435-43.

6. Rein DB, Wittenborn JS, Smith BD, Liffmann DK, Ward JW. The Cost-effectiveness, Health Benefits, and Financial Costs of New Antiviral Treatments for Hepatitis C Virus. Clin Infect Dis. 2015.

7. Koh C, Heller T, Haynes-Williams V, Hara K, Zhao X, Feld JJ, et al. Long-term outcome of chronic hepatitis $\mathrm{C}$ after sustained virological response to interferon-based therapy. Aliment Pharmacol Ther. 2013;37(9):887-94.

8. Watanabe S, Kobayashi Y, Kawata K, Noritake H, Chida T, Nagasawa M, et al. Long-term pegylated interferon monotherapy following 72 weeks of pegylated interferon and ribavirin in hepatitis C virus genotype-1-infected slow responders. Intern Med. 2015;54(3):273-9.

9. Sandoughdaran S, Alavian SM, Sharafi H, Behnava B, Salimi S, Mehrnoush L, et al. Efficacy of Prolonged Treatment With Pegylated Interferon (Peg-IFN) and Ribavirin in Thalassemic Patients With Hepatitis C Who Relapsed After Previous Peg-IFNBased Therapy. Hepat Mon. 2015;15(1):e23564.

10. European Association for the Study of the L. EASL Clinical Practice Guidelines: management of hepatitis C virus infection. $J$ Hepatol. 2011;55(2):245-64.

11. Dong ZX, Zhou HJ, Xiang XG, Guo SM, Zhuang Y, Zhao GD, et al. IL28B genetic variations are associated with treatment response of patients with chronic hepatitis $\mathrm{C}$ in a Chinese Han population. J Dig Dis. 2015;16(2):90-7.

12. Khubaib B, Idrees M, Afzal S, Wasim M. The genotype CC of IL28B SNP rs12979860 is significantly associated with sustained virological response in chronic HCV Pakistani patients.J Dig Dis. 2015.

13. Gill U, Aziz H, Gill ML. Rapid virological response tailors the duration of treatment in hepatitis $\mathrm{C}$ virus genotype 3 patients treated with pegylated interferon alfa-2a and ribavirin in Pakistan. Int $J$ Infect Dis. 2013;17(11):e1017-21.

14. Wisniewska-Ligier M, Pawlowska M, Pilarczyk M, Halota W, Wozniakowska-Gesicka T. Efficacy of pegylated interferon alpha-2b and ribavirin in chronic hepatitis $C$ virus (genotypes 1 and 4 ) infection. J Pediatr Gastroenterol Nutr. 2013;57(6):694-9.

15. Toyoda H, Kumada T, Shimada N, Takaguchi K, Ide T, Sata M, et al. Significance of a reduction in HCV RNA levels at 4 and 12 weeks in patients infected with HCV genotype $1 \mathrm{~b}$ for the prediction of the outcome of combination therapy with peginterferon and ribavirin. BMC Infect Dis. 2012;12:324.

16. Sezaki H, Suzuki F, Kawamura Y, Yatsuji H, Hosaka T, Akuta N, et al. Poor response to pegylated interferon and ribavirin in older women infected with hepatitis $C$ virus of genotype $1 \mathrm{~b}$ in high viral loads. Dig Dis Sci. 2009;54(6):1317-24. 


\section{Wu Q et al.}

17. Ghany MG, Nelson DR, Strader DB, Thomas DL, Seeff LB, American Association for Study of Liver D. An update on treatment of genotype 1 chronic hepatitis $C$ virus infection: 2011 practice guideline by the American Association for the Study of Liver Diseases. Hepatology. 2011;54(4):1433-44

18. Nguyen LH, Nguyen MH. Systematic review: Asian patients with chronic hepatitis $\mathrm{C}$ infection. Aliment Pharmacol Ther 2013;37(10):921-36.

19. De Nicola S, Aghemo A, Rumi MG, Galmozzi E, Valenti L, Soffredini R, et al. Interleukin 28B polymorphism predicts pegylated interferon plus ribavirin treatment outcome in chronic hepatitis $\mathrm{C}$ genotype 4. Hepatology. 2012;55(2):336-42.

20. Sarwar S, Ryan EJ, Iqbal M, McCormick PA, O'Farrelly C, Hegarty J. Rapid, early and sustained virological responses in a cohort of Irish patients treated with pegylated interferon and ribavirin for chronic hepatitis C virus infection. Ir J Med Sci.2012;181(1):53-8.

21. Fried MW, Hadziyannis SJ, Shiffman ML, Messinger D, Zeuzem S.
Rapid virological response is the most important predictor of sustained virological response across genotypes in patients with chronic hepatitis C virus infection. J Hepatol. 2011;55(1):69-75.

22. Milan M, Boninsegna S, Scribano L, Lobello S, Fagiuoli S, Fabris P et al. Viral kinetics during the first weeks of pegylated interferon and ribavirin treatment can identify patients at risk of relapse after its discontinuation: new strategies for such patients? Infection. 2012;40(2):173-9.

23. Kurosaki M, Hiramatsu N, Sakamoto M, Suzuki Y, Iwasaki M, Tamori A, et al. Age and total ribavirin dose are independent predictors of relapse after interferon therapy in chronic hepatitis $C$ revealed by data mining analysis. Antivir Ther. 2012;17(1):35-43.

24. Tsui JI, Currie S, Shen H, Bini EJ, Brau N, Wright TL, et al. Treatment eligibility and outcomes in elderly patients with chronic hepatitis C: results from the VA HCV-001 Study. Dig Dis Sci. 2008;53(3):809-14. 